\title{
A compact conductor-backed CPW-based dual bandpass filter for satellite S-band and C-band
}

\author{
S. Oudaya Coumar ${ }^{1 *}$ and S. Tamilselvan ${ }^{2}$
}

\author{
*Correspondence: \\ oudaya.mtechece@pec.edu \\ ${ }^{1}$ Vignan Lara Institute \\ of Technology and Science, \\ Guntur, Andhra Pradesh, \\ India \\ Full list of author information \\ is available at the end of the \\ article
}

\begin{abstract}
An efficient and compact dual bandpass filter having single narrow rejection band between S-band and C-band using CPW arrangement is proposed. The half wavelength square resonator is used in ground surface to eliminate certain frequency bands. The transmission zero of rejection band is restricted by modifying the dimension of the resonator. The CPW-based DB-BPF is simulated and tested with its equivalent prototype. This work emphasizes DB-BPF with square resonator coupling constructed on CPW process. An innovative integration of circular resonator incorporated with inter-digital line coupling in the top surface of the substrate and square resonator at the bottom surface of the substrate produces wide band and narrow stop band, respectively. The DB-BPF has remarkable bandwidth from 2 to $3.8 \mathrm{GHz}$ and 4.3 to $7.8 \mathrm{GHz}$ as S-band and C-band, respectively. Hence, the overall bandwidth of the filter is $5.3 \mathrm{GHz}(1.8 \mathrm{GHz}$ and $3.5 \mathrm{GHz})$. The filter performances are evaluated and analyzed through the factors like S-parameters, Q-factor and group delay. The overall dimension of DB-BPF is achieved to be $(39 \times 4.5 \times 1.6) \mathrm{mm}^{3}$, which is very much compact in dimension. The filter characteristics show the return loss of $-35.2 \mathrm{~dB}$ and insertion loss of $-1.2 \mathrm{~dB}$ which are validated by measured results.
\end{abstract}

Keywords: Coplanar waveguide (CPW), Microstrip (MS), Dual-band filter (DB-BPF), Resonator, Insertion loss (IL), Return loss (RL), Group delay

\section{Introduction}

RF filter circuits are generally in use in microwave system for the mitigation of spurious frequencies from other services. Bandpass filters are responsible for suppressing such spurious frequencies and higher-order harmonics in pass band [1]. The performances of filters are studied from the parameters like miniaturized geometry, intended pass band and attenuation band. Dual-band filters are most inevitable element in designing satellite communication model. S-band and C-band range is predominantly allocated for mobile services in satellite communication. So, BSFs are designed by metallic pattern at the backside of coplanar waveguide $(\mathrm{CPW})$ structure [2].

CPW planar method is the most appropriate for designing satellite band filters because of easy integration with active and lumped elements. Metallic pattern-backed DB-BPF with coupling structure has been developed and demonstrated in Xiao et al. [3].

\section{Springer Open}

(0 The Author(s) 2020. This article is licensed under a Creative Commons Attribution 4.0 International License, which permits use, sharing, adaptation, distribution and reproduction in any medium or format, as long as you give appropriate credit to the original author(s) and the source, provide a link to the Creative Commons licence, and indicate if changes were made. The images or other third party material in this article are included in the article's Creative Commons licence, unless indicated otherwise in a credit line to the material. If material is not included in the article's Creative Commons licence and your intended use is not permitted by statutory regulation or exceeds the permitted use, you will need to obtain permission directly from the copyright holder. To view a copy of this licence, visit http://creativeco mmons.org/licenses/by/4.0/. 
Filter design deals with the optimization of stub length and slot width to generate discontinuity and thereby the filter achieves C-band frequency from (4 to 8) GHz [4]. Sharp selectivity with low loss is achieved by various low-pass and high-pass stub employed between resonators where inductive and capacitive components exist due to strips on both sides. The size of the filter is reduced to a greater extent due to increased inductance and capacitance, named as slow-wave effect [5].

CPW planar technology is defined as a series stub which is arranged by introducing discontinuity in the middle stub and slot generated from the middle stub on either sides of ground $[6,7]$. An open circuit is created at the discontinuity which short circuits the input port whose length is $\lambda_{\mathrm{g}} / 4$ of the stub, where $\lambda_{\mathrm{g}}$ is the resonant wavelength [8]. For exhibiting band-stop response, this wavelength is more responsible. The distinctive features of the CPW model predominantly depend on the length and if the value of length is close to $\lambda_{\mathrm{g}} / 4$, then the circuit will act as a resonant circuit of resonating frequency and if the length is very small $\left(<\lambda_{\mathrm{g}} / 10\right)$, then the circuit will perform as a capacitance circuit. Thus, the length of the stub should be necessarily to be $\lambda_{\mathrm{g}} / 4$ [9].

To achieve such high-frequency band, transition from microstrip to CPW technique will be the best choice to adopt $[10,11]$. Transition from microstrip to CPW without connecting wires is an emerging new technique to create more interest among researchers. This hybrid MS-CPW technology offered some advantage over traditional narrowband planar technology. To list few, they have very large bandwidth, low power requirements, less propagation delay, invulnerability in multipath propagation and compact circuit design. The famous known feeding mechanism is said to be CPW feed methodology which offers lower loss and low radiation leakage.

In this work, a compact CPW-based DB-BPF with resonator integrated with coupling lines and backed with metallic pattern is designed, simulated, verified and investigated. DB-BPF achieved response with sharp transition between pass band and attenuation band in reduced dimension. The proposed conductor-backed CPW DB-BPF is unique in design and simple in geometry when compared with available filter geometry in the literature.

\section{Filter design methods and analysis}

Radius of circular resonator is,

$$
\begin{aligned}
& a=\frac{F}{\sqrt{\left\{1+\frac{2 h}{\pi \varepsilon_{r} F}\left[\ln \left(\frac{\pi F}{2 h}\right)+1.7726\right]\right\}}} \\
& F=\frac{8.791 \times 10^{9}}{f \sqrt{ } \varepsilon_{r}}
\end{aligned}
$$

Effective radius of circular resonator is,

$$
a_{e}=a \sqrt{\left\{1+\frac{2 h}{\pi \varepsilon_{r} a}\left[\ln \left(\frac{\pi a}{2 h}\right)+1.7726\right]\right\}}
$$

So, resonant frequency for dominant $\mathrm{TM}_{110}^{\mathrm{z}}$ is obtained from 


$$
f_{\mathrm{r}}=\frac{1.8412 c}{2 \pi a_{e} \sqrt{ } \varepsilon_{r}}
$$

Theoretical resonant frequency is expressed as

$$
\begin{aligned}
& 2 \pi r=n \lambda_{\mathrm{g}} \\
& f_{0}=\frac{n C}{2 \pi r \sqrt{\varepsilon_{\text {reff }}}}
\end{aligned}
$$

where $\lambda_{\mathrm{g}}$ - guide wavelength, $a$-mean side of hexagon, $n-$ number of modes, $f_{\mathrm{r}}-$ resonant frequency, $c$-speed of light in free space, $\varepsilon_{\text {reff }}-$ effective dielectric constant.

Filter topology has input/output feed lines, perfectly matched coupling lines and resonator for sustained oscillations [12]. Figure 1 shows concentric closed ring resonator model. Signal power is fed at one port, and output power is measured at other port since the circuit is symmetrical. Resonant frequencies of ring resonator will keep fluctuating unless the large gap is maintained between feed lines and resonator. This coupling is named as weak coupling [13-16] which has less value of capacitance between coupling lines. The coupling is strong when the cavity between feed lines and resonator structure is minimum which in turn increases capacitances [17]. This effect makes deviation in resonant frequencies from actual frequency of resonator. Resonance condition occurs only if the average value of all sides of ring resonator is identical to that of integral multiple of $\lambda_{\mathrm{g}}[18,19]$ which allow the signal to propagate across the structure. In initial mode, field will be maximum at coupling discontinuity and no field at its normal plane.

\section{Filter design}

Geometric layout of compact metallic pattern-backed CPW-based DB-BPF using ring resonator for S-band and C-band is shown in Fig. 2. The DB-BPF is simply comprised of circular resonator and square ring resonator structure at ground plane and constructed using FR4 of $1.6 \mathrm{~mm}$ height and relative permittivity 4.4. Typical geometric values of DB-BPF are given in Table 1 . The DB-BPF circuit consists of four elements, namely circular resonator, inter-digital coupling lines on both sides, feed lines at both ports for 50 ohms and backed square ring conductor. The inter-digital link is coupled with circular MMR (multi-mode resonator) to produce widespread bandwidth and improved filter performances [20, 21].

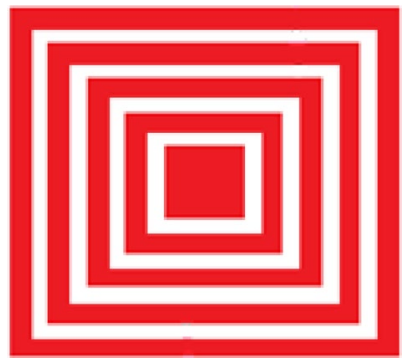

Fig. 1 Ring resonator structure 


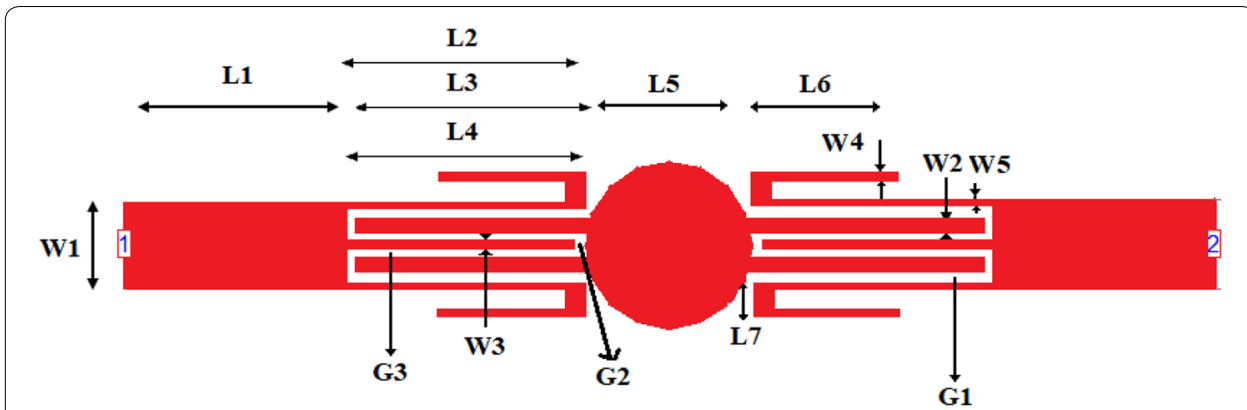

a Top view

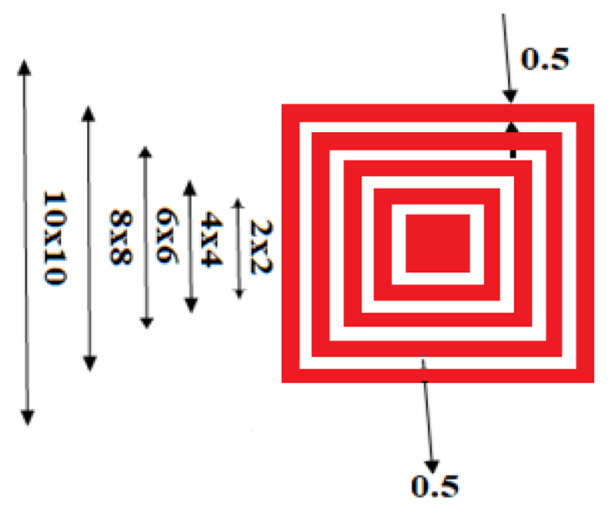

b Bottom view

Fig. 2 Design of DB-BPF

Table 1 Optimal geometric values of DB-BPF

\begin{tabular}{|c|c|c|c|c|c|}
\hline Filter element & Description & Dimensions & Filter element & Description & Dimensions \\
\hline L1 & Length of feed line & 8 & G1, G3 & $\begin{array}{l}\text { Inter-digital coupling } \\
\text { gap }\end{array}$ & 0.3 \\
\hline L2 & $\begin{array}{l}\text { Length of inter-digital } \\
\text { coupling }\end{array}$ & 8.3 & G2 & $\begin{array}{l}\text { Coupling line resona- } \\
\text { tor gap }\end{array}$ & 0.4 \\
\hline L3 & $\begin{array}{l}\text { Length of middle inter- } \\
\text { digital coupling }\end{array}$ & 6 & W1 & Width of feed line & 3.2 \\
\hline L4 & $\begin{array}{l}\text { Length of outer inter- } \\
\text { digital coupling }\end{array}$ & 8.2 & W2 & $\begin{array}{l}\text { Width of inter-digital } \\
\text { coupling }\end{array}$ & 0.5 \\
\hline L5 & $\begin{array}{l}\text { Diameter of circular } \\
\text { resonator }\end{array}$ & 5 & W3 & $\begin{array}{l}\text { Width of middle inter- } \\
\text { digital coupling }\end{array}$ & 0.3 \\
\hline L6 & Length of open stubs & 3.5 & W4 & Width of open stub & 1 \\
\hline L7 & Height of open stubs & 1 & W5 & $\begin{array}{l}\text { Width of outer cou- } \\
\text { pling line }\end{array}$ & 0.2 \\
\hline
\end{tabular}

All dimensions are in $\mathrm{mm}$

Multi-mode resonator and inter-linked coupling are combined together and produce continuous oscillation for the range of frequencies $2 \mathrm{GHz}-7.8 \mathrm{GHz}$ restricted to S-band and C-band. Tuning of desired bandwidth is obtained with support of resonator at ground plane which eliminates certain frequencies in pass band so that the filter responds as dual-band BPF. Stop band width and extent of rejecting certain frequencies depend on number of rings in ground plane. Parametric optimization is carried out 
on filter circuit in order to obtain the desired pass band and stop band. Thickness and length of stubs are also a factor in determining the desired band. Simulation of filter geometry is carried out by Ansoft HFSS. Many complicated circuits with complex topology exist in the literature [22, 23], however, proposing that DB-BPF topology performs well in terms of S-parameter, bandwidth and dimension on comparing with existing complex structures. DB-BPF can also be referred as hybrid circular and square resonator circuits which are implemented in the form of transmission line and waveguide structures [24]. The CPW structure in the design is responsible for tuning the bandwidth. The topology is optimized for satellite band frequency.

\section{Results and discussion}

CPW-based DB-BPF prototype is obtained for the above design values. The filter characteristics are investigated for $\mathrm{S}$ - and $\mathrm{C}$-band range by tuning various filter attributes on various elements that are analyzed. The filter geometry is optimized for different attributes like length, width and thickness of the strip for various values that are analyzed.

Scattering parameters $\left(S_{21}\right.$ and $S_{11}$ ), insertion loss (IL) and return loss (RL) of the proposed S-band and C-band filter based on CPW method are studied. The simulated frequency response of single-mode resonant cell with concentric rings in single cell is shown in Fig. 3. S-band and C-band filters are optimized for various parameters like length, width and strips values. The cell with five levels of ring is assumed to be the optimized design. Figure 4 depicts clearly that the $\mathrm{S}$-band and C-band filters have excellent IL of $-1.2 \mathrm{~dB}$ and extremely low RL of $-35.2 \mathrm{~dB}$ is obtained.

DB-BPF obtains remarkable pass band (2-3.8) $\mathrm{GHz}$ and (4.3-7.8) $\mathrm{GHz}$ as S-band and $\mathrm{C}$-band, respectively. The phase variation response of $\mathrm{S}$-band and $\mathrm{C}$-band filter based on $S_{21}$ values is evidently displayed in Fig. 5. It is obvious that the DB-BPF has outstanding in-phase characteristics in pass band. Figure 6 shows the comparison analysis of simulated results with mathematical modeling. The mathematical model of DB-BPF is obtained from design expression given in Eqs. (1)-(6). Mathematical model

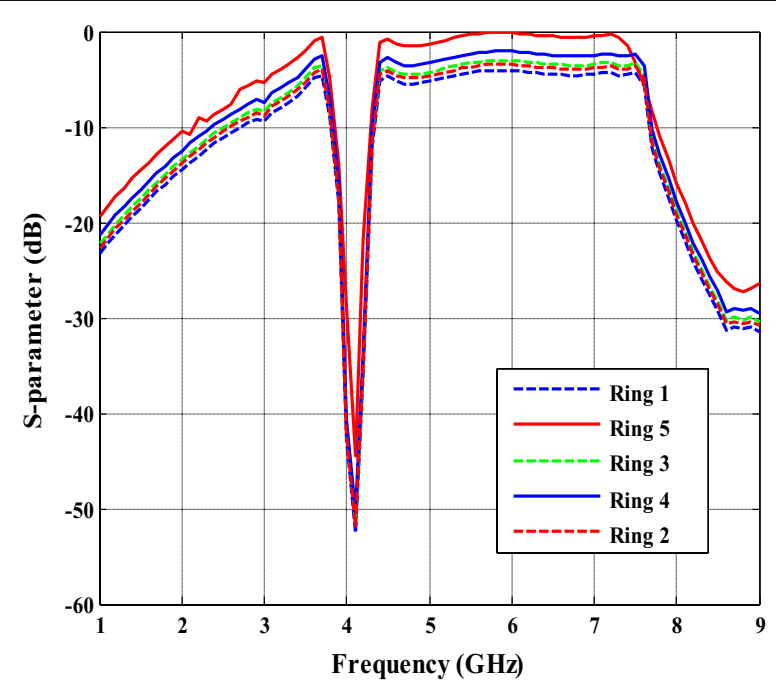

Fig. 3 Optimized $\mathrm{S}_{21}$ response of DB-BPF 


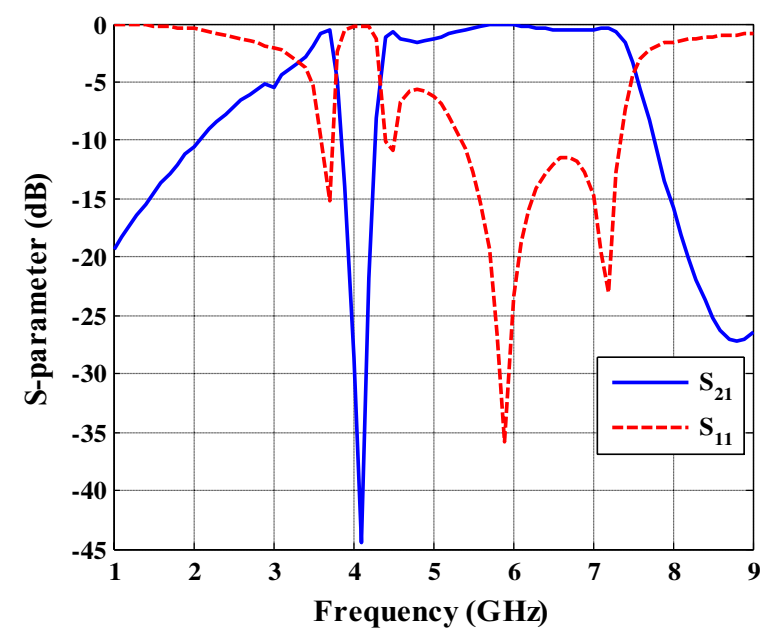

Fig. 4 Simulated $S_{11}$ and $S_{21}$ of DB-BPF

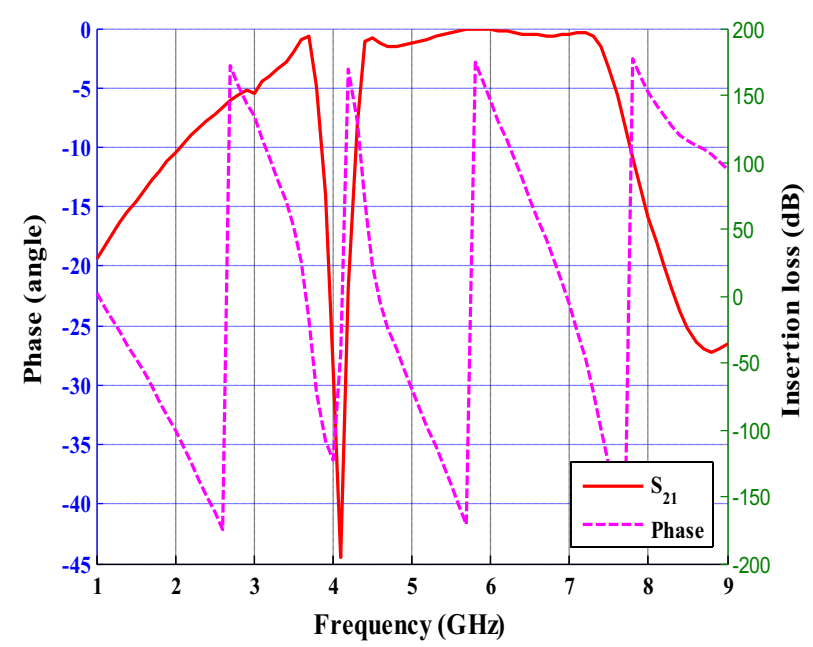

Fig. 5 Simulated phase versus $S_{21}$ of DB-BPF

is the theoretical analysis carried out for validating the filter response. The mathematical expressions satisfy the band-stop characteristics. However, these expressions will realize only approximate results when compared with simulated and measured results. As far as DB-BPF is concerned, measured results obey the simulated results, and hence, those results are strongly considered for real-time implementations rather than mathematical results. However, for the sake of validating the filter design, the mathematic model results are verified with simulated results.

The $Q$-factor is a dimensionless quantity that shows the level of sustained oscillations in pass band for maximum duration. The $Q$-factor response of DB-BPF over frequency using Eq. (7) is shown in Fig. 7. The analysis of uniform group delay is unavoidable and desired for satellite applications. Figure 8 depicts simulation group delay performance of DB-BPF which implies excellent linear signal transfer. The typical value of group delay obtained is $<3 \mathrm{~ns}$ in pass band. 


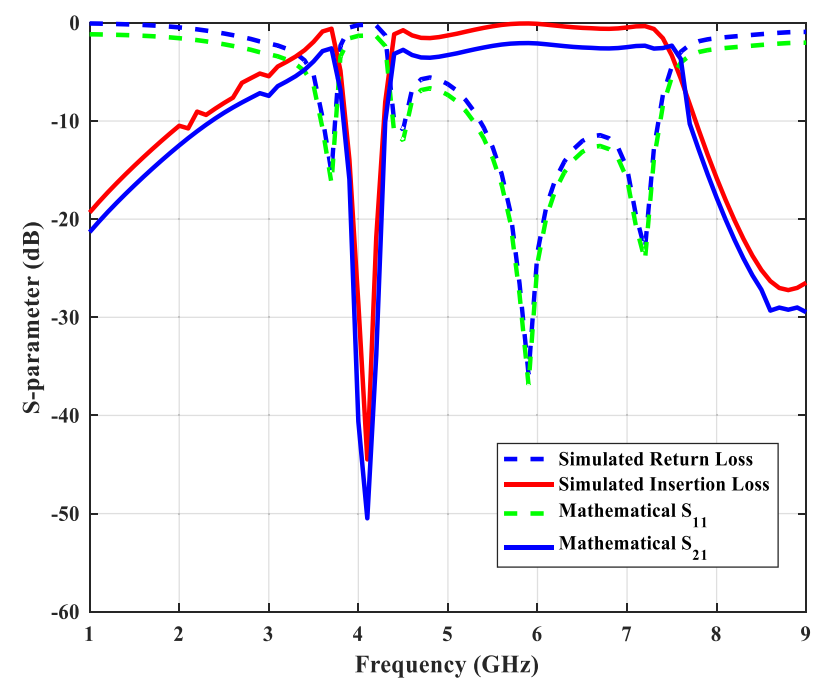

Fig. 6 Simulated S-parameter versus mathematical values of DB-BPF

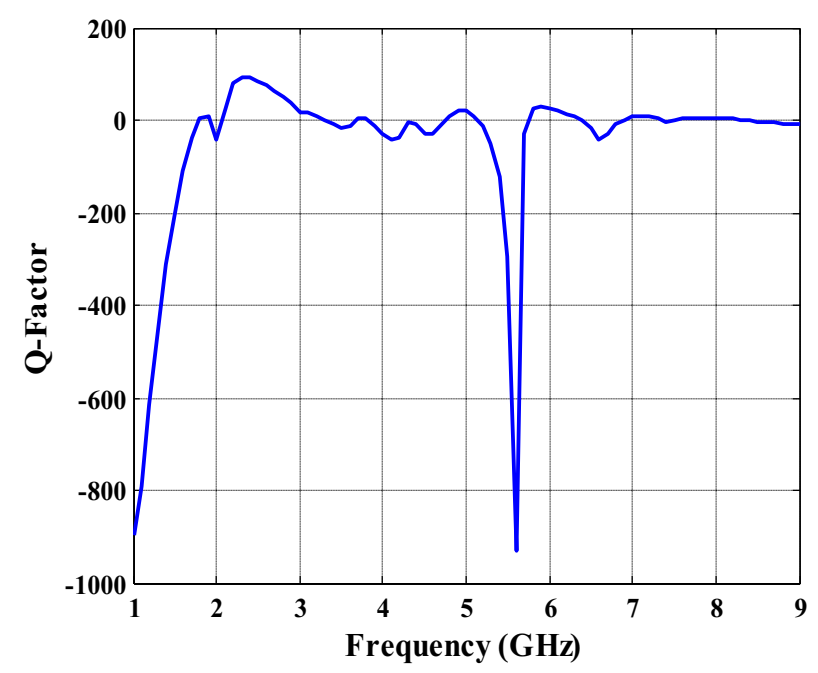

Fig. 7 Simulated Q-factor of DB-BPF

$$
Q=\frac{2 f_{0}}{B W}
$$

The prototype realization of top and bottom surface of DB-BPF is displayed in Fig. 9. The insertion and return loss readings of filter prototype are studied using network analyzer, Model HP8757D, and compared with simulated outcomes, as shown in Figs. 10 and 11, respectively. A decent agreement prevails between simulated as well as measured outcomes. The proposed DB-BPF has bandwidth (from 2 to 7.8 ) $\mathrm{GHz}$ at $-10 \mathrm{~dB}$ line with a stop band between 3.8 and $4.3 \mathrm{GHz}(0.5 \mathrm{GHz})$ with fractional bandwidth of $120 \%$ calculated from bandwidth and resonant frequency. 


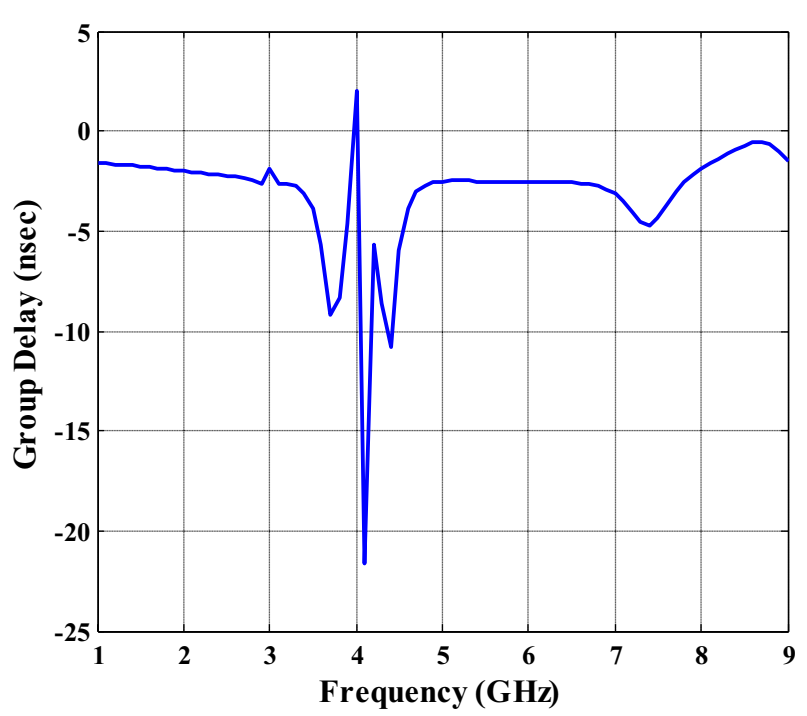

Fig. 8 Group delay response of DB-BPF

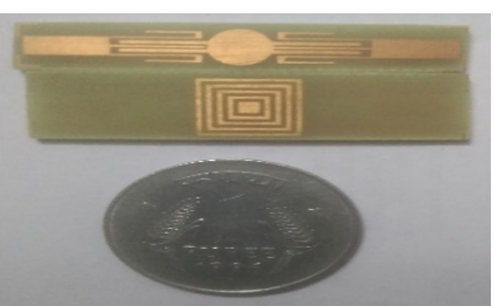

Fig. 9 Prototype of DB-BPF

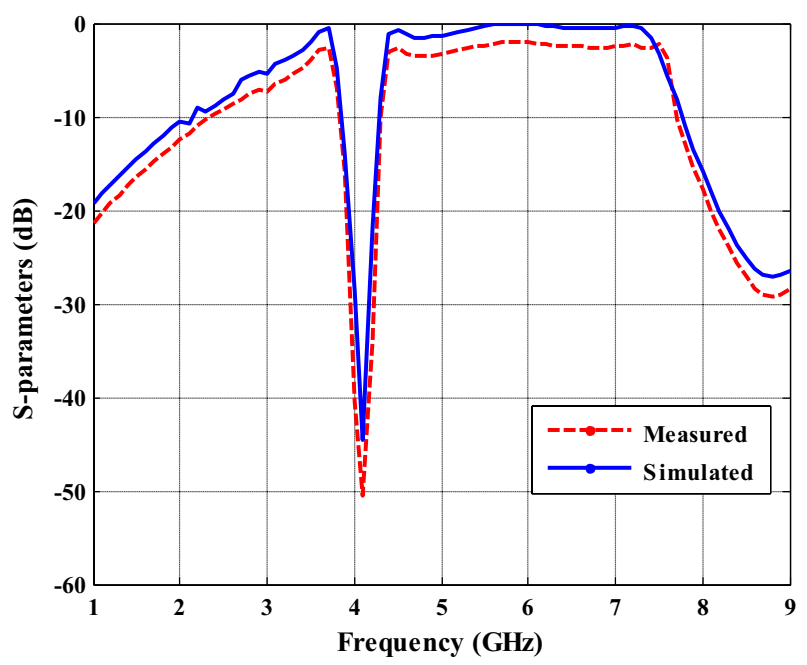

Fig. 10 Simulated and measured $S_{21}$ of DB-BPF 


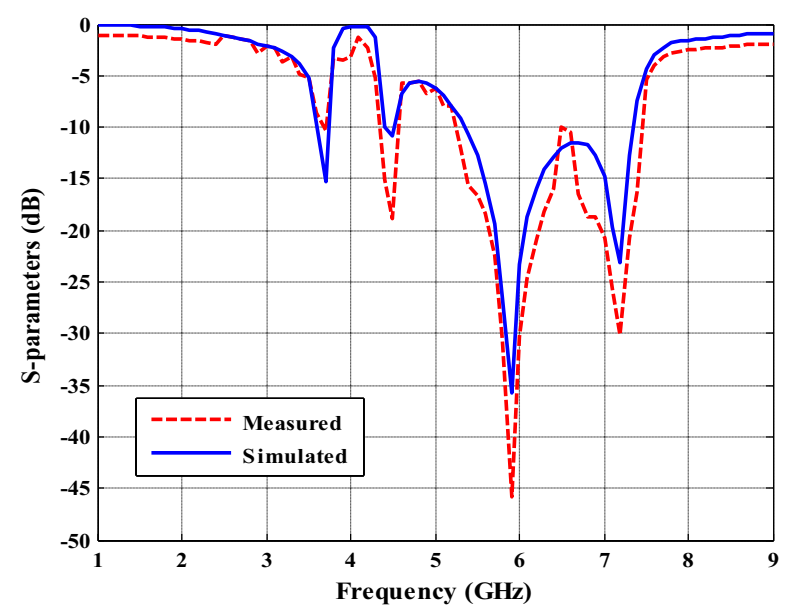

Fig. 11 Simulated and measured $S_{11}$ of DB-BPF

Table 2 Comparison of investigated DB-BPF with existing filters

\begin{tabular}{lllll}
\hline References & $\begin{array}{l}\text { Insertion loss }\left|\mathbf{S}_{\mathbf{2 1}}\right| \\
(\mathbf{d B})\end{array}$ & $\begin{array}{l}\text { Return loss }\left|\mathbf{S}_{\mathbf{1 1}}\right| \\
\mathbf{( d B})\end{array}$ & Pass band $(\mathbf{G H z})$ & Size $(\mathbf{m m})^{\mathbf{2}}$ \\
\hline Qi Duan et al. & -0.8 & -30 & 4.5 & 195.61 \\
Shanming et al. & -1 & -35 & 1.2 & 732.16 \\
Zhenyu et al. & -4 & -34 & 0.5 & 485 \\
Yien et al. & -4.5 & -25 & 0.4 & 900 \\
This work & -1.2 & -35.2 & $(2-3.8)$ and $(4.3-7.8)$ & 175.5 \\
\hline
\end{tabular}

Table 2 summarizes the comparative study on fundamental performance parameters like IL, RL, pass band and geometry of DB-BPF with other existing filters. It is evident that the DB-BPF performs well in terms of scattering parameter $\left(S_{11}\right.$ and $\left.S_{21}\right)$, and dual pass band with reduced size is achieved. The $S$-parameter values are also good when compared with the other LPFs listed in the reference.

\section{Conclusion}

A compact metallic conductor-backed CPW-based DB-BPF using ring resonator is studied in this work. The filter has pass band (2-7.8) GHz with stop band (3.8-4.3) GHz in $\mathrm{S}$-band and C-band. The circular resonator and inter-linked coupling lines are optimized for the best performance in S- and C-bands. Design, simulation and performance characteristics of DB-BPF are deliberately analyzed and discussed. DB-BPF demonstrates uniform bandwidth (2-7.8) GHz and fractional bandwidth of $120 \%$ with return loss and insertion loss of $-35.2 \mathrm{~dB}$ and $-1.2 \mathrm{~dB}$, respectively. Thus, DB-BPF shows better performance than the existing ones and is optimally suited for satellite band applications.

Abbreviations

CPW: Coplanar waveguide; MS: Microstrip; DB-BPF: Dual-band bandpass filter; IL: Insertion loss; RL: Return loss. 


\section{Authors' contributions}

S. Oudaya Coumar (S.O.) and S. Tamilselvan (S.T.) conceived the presented idea on CPW-based BPF for satellite applications. S.O. developed the theory and performed the design computations dual-band filter. S.T. verified the analytical methods and encouraged S.O. to investigate on CPW-based bandpass filter for S- and C-band satellite applications and supervised the findings of this work. All authors discussed the results and contributed to the final manuscript. S.O. planned and carried out simulations and fabricated the CPW-based dual-band filter for satellite band. S.O. and S.T. carried out the practical measurements of filter parameters. S.O. wrote the manuscript with support from S.T. S.T. supervised the project and contributed to the interpretation of the results. S.O. developed the theoretical formalism, performed the analytic calculations and performed the numerical simulations. Both S.O and S.T. contributed to the final version of the manuscript. All authors provided critical feedback and helped shape the research, analysis and manuscript. All authors read and approved the final manuscript.

\section{Funding}

Not applicable.

Availability of data and materials

Not applicable.

\section{Competing interests}

The authors declare that there is no conflict of interest in this paper.

\section{Author details}

${ }^{1}$ Vignan Lara Institute of Technology and Science, Guntur, Andhra Pradesh, India. ${ }^{2}$ Pondicherry Engineering College, Puducherry, India.

Received: 19 September 2019 Accepted: 18 March 2020

Published online: 01 April 2020

\section{References}

1. Ludwig R, Bretchko P (2000) RF circuit design theory and applications. Prentice-Hall, Englewood Cliffs

2. Guo Z, Yang T (2017) Novel compact ultra-wideband band pass filter based on via-less vertical CPW/microstrip transitions. IEEE Trans Microw Theory Technol 53(18):1258-1260

3. Xiao J-K, Zhu M, Ma J-G, Hong J-S (2016) Conductor-backed CPW band pass filters with electromagnetic couplings. IEEE Microw Wirel Compon Lett 26(6):401-403

4. Borja AL, Carbonell J, Boria VE, Cascon J, Lippens D (2010) A 2\% bandwidth C-band filter using cascaded split ring resonators. IEEE Antennas Wirel Propag Lett 9:256-259

5. Le Coq M, Rius E, Favennec J-F et al (2015) Miniaturized C-band SIW filters using high-permittivity ceramic substrates. IEEE Trans Compon Packag Manuf Technol 5(5):620-626

6. Selga J, Gil M, Aznar F, Bonache J, Martin F (2010) Composite right-left-handed coplanar waveguides loaded with split ring resonators and their application to high-pass filters. IET Microw Antennas Propag 4(7):822-827

7. Duran-Sindreu M, Bonache J, Martin F (2010) Compact elliptic-function coplanar waveguide low-pass filters using backside metallic patterns. IEEE Microw Wirel Compon Lett 20(11):601-603

8. Li D, Yaqing Yu et al (2019) Design of compact quad-band band pass filter with good selectivity using two-/trisection SIRs and stepped impedance inverters. IET Microw Antennas Propag 13(5):675-682

9. Horestani AK et al (2014) Coplanar waveguides loaded with s-shaped split-ring resonators: modeling and application to compact microwave filters. IEEE Antennas Wirel Propag Lett 13:1349-1352

10. Gholipour V, Moshiri SMM, Alighanbari A, Yahaghi A (2016) Highly selective wideband band pass filter using combined microstrip/coplanar waveguide structure. IET Microw Antennas Propag 52(13):1145-1147

11. Chou Y-T, Lu H-C (2013) Magnetic near-field probes with high- pass and notch filters for electric field suppression. IEEE Trans Microw Theory Technol 61(6):2460-2470

12. Naghar A et al (2015) Design of compact wideband multi-band and ultra-wideband band pass filters based on coupled half wave resonators with reduced coupling gap. IET Microw Antennas Propag 9(15):1786-1792

13. Mohammadi B et al (2015) New design of compact dual band-notch ultra-wideband band pass filter based on coupled wave canceller inverted T-shaped stubs. IET Microw Antennas Propag 9(1):64-72

14. Lin L, Yang S, Sun S-J, Bian W, Liang C-H (2014) Ultra-wideband band pass filter using multi-stub-loaded ring resonator. IET Electron Lett 50(17):1218-1220

15. Oudaya Coumar S, Tamilselvan S (2019) Miniaturized conductor backed CPW high pass filter for C-band satellite applications. Microw Opt Technol Lett MOTL 61(6):1478-1481

16. Oudaya Coumar S, Tamilselvan S (2019) Development of open stub loaded square resonator based dual band filter with a Notch band to reject 802.11a. J Mater Today 11(3):1144-1151

17. Elsheikh MAG, Safwat AME (2019) Wide band modeling of SRR-loaded coplanar waveguide. IEEE Trans Microw Theory Tech 67(3):851-860

18. Janković $N$ et al (2016) Compact UWB band pass filter based on grounded square patch resonator. IET Electron Lett 52(5):372-374

19. Song QDK, Chen F, Fan Y (2015) Compact dual-band band pass filter using simply hybrid structures. IET Electron Lett 51(16):1265-1266

20. Guan X, Le C et al (2019). Compact dual-band HTS band pass filter using coplanar waveguide short-circuited stubloaded ring resonator. IEEE Trans Appl Supercond 29(5), Art. no. 1500704

21. Contreras A, Ribo M et al (2018) Compact fully uni-planar band stop filter based on slow-wave multimodal CPW resonators. IEEE Microw Wirel Compon Lett 28(9):780-782 
22. Saghati AP, Batra JS, Kameoka J, Entesari K (2015) A miniaturized microfluidically reconfigurable coplanar waveguide band pass filter with maximum power handling of 10 watts. IEEE Trans Microw Theory Technol 63(8):2515-2525

23. Lin S, Wang J, Zhang G, Hong J (2015) Design of microstrip tri-mode balun band pass filter with high selectivity. IET Electron Lett 51(13):998-999

24. Oudaya Coumar S, Tamilselvan S (2018) Fabrication design of axially rotated square resonator based compact ultrawideband BPF using tight coupling. J Comput Theor Nano Sci 15(5):1695-1699

\section{Publisher's Note}

Springer Nature remains neutral with regard to jurisdictional claims in published maps and institutional affiliations.

Submit your manuscript to a SpringerOpen ${ }^{\circ}$ journal and benefit from:

- Convenient online submission

- Rigorous peer review

- Open access: articles freely available online

- High visibility within the field

Retaining the copyright to your article

Submit your next manuscript at $\boldsymbol{s p r i n g e r o p e n . c o m ~}$ 